\title{
SOCIEDADE BRASILEIRA DE NEUROLOGIA, PSIQUIATRIA E MEDICINA LEGAL (RIO DE JANEIRO)
}

\author{
SECÇAO DE NEUROLOGIA *
}

\author{
Sessão ordinária - 3, Maio, 1943
}

PRESIDENTE - DR. PAULO ELEJALDE

\begin{abstract}
Forma particular de discinesia dos músculos da face e fonadores. Dr. A.
\end{abstract} Austregésilo Filho.

Trata-se de um paciente, portador de espasmos lábio-glosso-faríngeos que tornam a articulação da palavra dificil, quasi ininteligivel. Fazia uso das bebidas. alcoólicas. Teve um ictıs. Após a volta á conciencia, foi vítima de halucinações. Passado o período halucinatório apresentou distúrbios da marcha que desapareceram. Atualmente apresenta apenas os espasmos pré-citados.

Dr. Olavo Nery - comenta o caso, lembrando um de A. Jakob, de hipercinesia da face em que, à autópsia, foram encontradas lesões do núcleo caudado. Este fato levou o referido autor a admitir uma somatotopia do núcleo lenticular. Refere-se tambem à doutrina de Wilson sobre a dupla inervação da face: piráiiidal e extra-piramidal.

Dr. Paulo Elejalde - comenta o fato de que os espasmos só surgem ao tentar o paciente falar e não nos movimentos isolados.

Dr. Austregésilo Filho responde, mostrando que os espasmos são realmente ria articulação da palavra (disartria), o que o leva a pensar tratar-se de lesão tilateral dos núcleos extra-piramidais.

Causalgia, cura cirúrgica. Dr. J. Ribe Portugal.

Paciente de 18 anos, que fora ferido à faca no dorso da mão esquerda. Foi-lhe feita a sutura dos tendôes e da pele. Cerca de um mês depois do acidente, retornou ao Hospital da Ordem do Carmo, Serviço de Cirurgia. Apresentava cior espontânea, sensação de queimadura e cianóse nos dedos e em toda a mão. Péle brilhante e lusidia (glossy-skin). Diagnóstico: Causalgia. Praticada a remoção da cicatriz na qual se achavam englobados varios filetes nervosos sensitivos, a cura foi rápida. As dores desapareceram e todos os movimentos foram recuperados prontamente.

Gomas sifiliticas simulando tumor intra-medular. Dr. Paulo Elejalde.

$\mathrm{Em}$ antigo sifilítico tratado, com reação de Wassermann negativa nc sangue, instalou-se, de modo sub-agudo, paraplegia flácida seguida de paresia dos membros superiores. Bloqueio parcial do espaço sub-aracnoideo à prova de Queckensted-Stookey; miélografia lipiodolada com imagem típica de tumor intra-medular na região cervical. Líquido céfalo-raquidiano sem aumento de células e aumento de globulinas; reação de Wassermann negativa com $1 \mathrm{cc}$. Intervenção cirúrgica nelo Prố. Rivadavia Gusmão; retirada de dois pequenos tumores bem individualizados. Morte dias depois por infeç̧ão das vias urinárias. $\mathrm{O}$ exame histopatológico mostrou tratar-se de granulomas luéticos, sendo pequena a reação inflamatória meníngea e do tecido medular circundante. Teceu o autor algumas considerações scbre o caso.

(*) Notas fornecidas gentilmente, pelo Dr. Olavo Nery, secretário da Secção. 
Miélodisplasia. Dr. A. Austregésilo Filho.

A propósito de um caso documentado com varios cortes de medula, o comunicante tece comentários em torno da chamada miélodisplasia. Salienta a importância da espinha bífida oculta. . Refere três outros casos clínicos. Discorre sobre os defeitos da embriogtenese do sistema nervoso. Propõe um termo genérico que abrangeria a miélo e a encéfalodisplasia: a neurodisplasia.

Dr. J. Ribe Portugal - indaga si não fora encontrada, no cerebelo, a malformação de Arnold - Chiari.

Dr. Antonio R. de Mello - lembrando seus casos em colaboração com $\sigma$ Prof. Austregésilo, fala sobre os status dysraphicus entre os quais, seguindo osautores franceses, inclue a siringomielia.

Dr. Paulo Elejalde refere os estudos modernos de embriologia experimental nos quais se obtem a formação de mais de uma medula por indução provocada por corpo estranho sobre os tecidos visinhos.

\section{Sessão ordinária -7 , Junho, 1943}

Meningioma da região pré-motora. Drs. J. Ribe Portugal e Olavo Nery.

Enfermo de 43 anos de idade, vem sendo acometido, ha 4 anos, de crises. convulsivas de tipo epilético. De início, as crises começavam pela mão direita e depois se generalizavam. Desde o princípio, começou a notar dificuldade em movimentar os membros do lado direito. Atualmente apresenta hemi-paresia direita. Não tem cefaléia nem vomitos, assim como não apresenta perturbações visuais. Manifesta ligeiros distúrbios da conduta. O exame revela paresia e hipertonia muscular acentuada nos membros do lado direito. Reflexo cutâneo- plantar abolido à direita e normal à esquerda. Reflexos patelares presentes e hipotônicos em ambos os lados. Ligeiros distúrbios sensitivos; parestesia e hipoestesia dolorósa na mão direita. Estado mental: distúrbios da conduta, gliscroidia, mória. Exame do liquor: pressão inicial de 150 (Claude) em decúbito horizontal; ligeira hipercitóse e hiperalbuminóse; reação de Wassermann negativa. Ao primeiro exame, o fundo de olho se mostrou normal. O segundo, realizado três mezes após, revelou discrétos sinais de papila de estase. Foi feito o diagnóstico dc tumor da região pré-rolândica, provavelmente meningioma. Feita a intervenção foi retirado um tumor pesando 15 gramas. O exame histológico mostrou tratar-se de meningioma pial tipo hemangio-endoteliomatoso (P. Elejalde). $O$ paciente, examinado 15 dias depois de operado, exibia nítidas melhoras no domínio da sensibilidade.

Dr. A. Austregésilo Filho - comenta o caso, dizendo que o mesmo constitue um elogio à neuro-cirurgia, devendo-se o bom resultado sobretuda ao diagnóstico precoce, antes que se instalassem as consequências da hipertensão intracraniana.

\section{Sessão ordinária - 5, Julho, 1943}

Tumor cístico do tálamo. Drs. J. Ribe Portugal e Paulo Elejalde.

Não foi fornecido resumo deste trabalho.

Miasthenia grazis.: Drs. Austregésilo Filho e Deusdedith Araujo.

Paciente de 27 anos de idade, portadora de miastenia grave, na qual foi feito minucioso estudo, inclusive dosagens do calcio, fosfatase, creatinina, creatina, glicose, reação de Wassermann no sangue, exames do liquor, urina, curva hemo-leucocitária, radiografias do crânio e do torax, exame elétrico e biópsia. Apesar 
de todos esses exames, não foi possivel esclarecer a exata causa etiológica. Terminando a apresentação, os autores passam em revista as varias doutrinas aventadas para a interpretação da miastenia.

Dr. Paulo Elejalde - cita um caso da bibliografia norte-americana em que a miastenia se acompanhava de um tumor do timo. Acredita que seja uma síndrome que pode ser determinada por diversas causas, entre as quais estaria o timo.

Torcicolo congênito. Dr. Olavo Nery.

Rapaz de 17 anos, portador de torcicolo congênito, não havendo na família, casos idênticos nem qualquer outra doença nervosa ou mental. Ignoradas as condições do nascimento. Entretanto, a sua mãe infcrmou-o de que, ao nascer, já apresentava a cabeça inclinada para o lado esquerdo. Ao exame diréto, verifica-se que o feixe clavicular do esterno-cleido-mastoideo está transformado em uma corda fibrósa que aproxima os pontos de inserção do músculo. $\mathrm{O}$ exame do sistema nervoso nada mais revelou de anormal. As radiografias da coluna cervical apresentavam aspécto normal e a da clavícula esquerda mostra exostóse nos pontos de inserção muscular. $O$ autor passa em revista as diversas modalidades de torcicolo que filia a três grupos causais: a) lesões periféricas; b) lesões centrais; c) de origem psicogênica. Enquadra o torcicolo congênito dentro do primeiro grupo. Expõe as quatro teorias que se propõem interpretar o meçanismo patogênico da referida afecção: a) origem degenerativa; b) origem disembriogênica; c) origem infecciósa; d) origem traumática. Atribue seu caso à origem traumática. O tratamento do torcicolo congênito é cirúrgico, do qual refere várias técnicas.

Dr. A. Austregésilo Filho - comenta, declarando acreditar ser de origem nervosa, isto é. disembriogênica, a afecção em apreço.

Dr. Frederico Mac Dowell - a título de contribuição casuística, refere uma observação publicada na Presse Médicale, de torcicolo de origem naso-faríngea.

Dr. Aluisio Marques - tece considerações em torno da distrofia em causa, relacionando-a com outras displasias regionais e mostrando as relações que estas devem ter com as perturbações de desenvolvimento do sistema nervoso central. 